\title{
Monitoring mature tomato (red stage) quality during storage using ultraviolet-induced visible fluorescence image
}

\author{
AUTHOR(S): \\ Konagaya, Keiji; Al Riza, Dimas Firmanda; Nie, Sen; Yoneda, \\ Minori; Hirata, Takuya; Takahashi, Noriko; Kuramoto, \\ Makoto; Ogawa, Yuichi; Suzuki, Tetsuhito; Kondo, Naoshi
}

\section{CITATION:}

Konagaya, Keiji ... [et al]. Monitoring mature tomato (red stage) quality during storage using ultraviolet-induced visible fluorescence image. Postharvest Biology and Technology 2020, 160: 111031.

\section{ISSUE DATE:}

2020-02

URL:

http://hdl.handle.net/2433/265524

\section{RIGHT:}

(c) 2020. This manuscript version is made available under the CC-BY-NC-ND 4.0 license

https://creativecommons.org/licenses/by-nc-nd/4.0/; The full-text file will be made open to the public on 01 February 2022 in accordance with publisher's 'Terms and Conditions for Self-Archiving'.; This is not the published version. Please cite only the published version. この論文は出版社版でありません。引用の際には出版社版をご確認ご利用ください。 


\section{Monitoring Mature Tomato (Red Stage) Quality During Storage Using Ultraviolet-Induced Visible Fluorescence Image}

Highlights

- Tomato quality degrades after the red stage, and time after the harvest is important.

- Fluorescence images were tested to monitor quality degradation nondestructively.

- Fluorescence images were effective to monitor tomato storage continuously.

- This approach can be used to monitor tomatoes under a nonideal temperature regime. 
1 Title

2 Monitoring Mature Tomato (Red Stage) Quality During Storage Using Ultraviolet-induced

3 Visible Fluorescence Image

4

$5 \quad$ Author names and affiliations

6 Keiji Konagaya ${ }^{\mathrm{a}}$, Dimas Firmanda Al Riza ${ }^{\mathrm{a}, \mathrm{b}^{*}}$, Sen Nie ${ }^{\mathrm{a}}$, Minori Yoneda ${ }^{\mathrm{a}}$, Takuya Hirata ${ }^{\mathrm{c}}$, Noriko

$7 \quad$ Takahashi $^{\mathrm{c}}$, Makoto Kuramoto ${ }^{\mathrm{d}}$, Yuichi Ogawa ${ }^{\mathrm{a}}$, Tetsuhito Suzuki ${ }^{\mathrm{a}}$, Naoshi Kondo ${ }^{\mathrm{a}}$

8

9 a Graduate School of Agriculture, Kyoto University, Kyoto 606-8267, Japan

10 b Department of Agricultural Engineering, Faculty of Agricultural Technology, University of

11 Brawijaya, Jl. Veteran 65145, Malang, Indonesia

12 c Graduate School of Agriculture, Ehime University, Ehime 790-8566, Japan

13

d Advanced Research Support Center, Ehime University, Ehime 790-8577, Japan

14

15

*Corresponding author: dimasfirmanda@ub.ac.id

16

17

18

19 


\section{Abstract}

21 The potential of UV-induced fluorescence imaging was investigated as a non-destructive tool to monitor postharvest quality degradation of tomatoes harvested at the red stage and stored at $25^{\circ} \mathrm{C}$. The fluorescence images (excitation at $365 \mathrm{~nm}$ ) were found to be a better indicator of tomato quality degradation than color images after color saturation. Tomatoes were stored at $25{ }^{\circ} \mathrm{C}$ for 9 d. The changes in color and fluorescence of tomato were evaluated by two types of images: Color and fluorescence images. A conventional colorimeter was also used for as a reference. Changes in the RGB ratio for these two types of images were opposite. In the color images, the $G$ ratio decreased rapidly for the initial 3 or $5 \mathrm{~d}$ and then stabilized afterwards. On the other hand, in the fluorescence images, the $\mathrm{G}$ ratio increased continuously up to $9 \mathrm{~d}$. Given that temperature conditions during transportation and storage of tomatoes is not always ideal, the results from this research provide the foundation for developing a postharvest monitoring system of mature tomato quality degradation. 


\section{Introduction}

Tomato (Solanum lycopersicum) is one of the most widely consumed agricultural products in the world. Mature red tomatoes taste better, thus peri-urban agriculture often targets the production of these red tomatoes in a number of countries. However, red tomatoes are sensitive to the damage since they are relatively soft compared to greenish tomatoes. Thus, postharvest losses can be an issue. The FAO (2011) reported postharvest losses for fruit and vegetables to be around $10 \%$ worldwide. To minimize these losses, non-destructive quality monitoring of red tomatoes is important. This monitoring would also ensure food safety, and thus benefit both the distribution chain and consumers.

Ideally, tomatoes are transported through the distribution chain, right up to the consumers in a cold chain system. However, such a cold chain is not always present during transportation and storage. In developing countries, such as those in Africa, only $10 \%$ of farmers are using a lowcost on-farm cooling system (Arah et al., 2015). This indicates that over $90 \%$ of farmers have no on-farm storage facilities and therefore store their harvested tomatoes at ambient conditions. Furthermore, even such a system does not cover the complete cold chain. The effects on tomato quality during this ambient storage are the target of this study.

Tomatoes harvested at the red stage have already attained most of components that contribute to flavor (taste and aroma) (Klee and Giovannoni, 2011). Firmness will, however, continue to decline due to the ripening process. In addition, organic acids will decrease after the red stage, (Chilson et al., 2011), as well as sugars as respiration of the fruit occurs (Fagundes et al., 2015). Thus, total quality, in terms of quality components and firmness, is prone to degradation after the red stage. This is also supported by a drop in sensory ratings after the red stage (Chilson et 
al., 2011). Monitoring tomato quality degradation after being harvested at the red stage is our focus.

One potential method to non-destructively monitor quality degradation of red tomatoes could be color imaging as the tomato becomes a deeper red (Ajlouni et al., 2001). Unfortunately, however, the red color of a tomato saturates during this phase, limiting its capability to monitor quality degradation of red tomatoes.

On the other hand, fluorescence, another aspect of color, has the potential to be used for nondestructively monitoring red tomatoes without the above limitation. The fluorescence is light emitted by substance after it is irradiated by light at a shorter wavelength. A number of fluorescent components in tomatoes have been enumerated using high performance liquid chromatography (HPLC). These studies have revealed that red tomatoes contain fluorescent compounds, such as carotenoids (Barba et al., 2006), flavonoids and other phenolic compounds (Slimestad and Verheul, 2009).

Some of these compounds are colorless (i.e. pigments that do not absorb light in the visible range) and thus will not be affected by red saturation, as in the color images. Thus, UV-induced fluorescence images could provide unmasked information the color images cannot provide. Furthermore, the content of such compounds have reported to change after being harvested at the light red stage (Toor and Savage, 2006). Thus, UV-induced fluorescence images have the potential to non-destructively monitor tomato quality degradation after the red stage.

To date, fluorescence properties of tomato have been studied using multiplex sensors, spectrofluorometers or laser-induced fluorophotometers (Baek et al., 2014; Clément et al., 2015; Hoffmann et al., 2015; Lai et al., 2007). They have demonstrated correlations between 
80 fluorescence properties and internal or external qualities associated with ripening in the preharvest phase, the existence of cracks or cultivar differences. Hoffmann et al. (2015) also monitored tomatoes during the postharvest storage using fluorescence, but for green harvested tomatoes. Lai et al. (2007) investigated fluorescence properties of red and over-ripe tomato using extraction; a destructive measurement procedure. To the best of our knowledge, no nondestructive procedure for investigating fluorescence component changes in intact mature red tomatoes has been reported.

In this study, UV-induced fluorescence images were examined as a non-destructive method with the objective of monitoring quality degradation of tomatoes harvested at the red stage and stored at ambient temperature. These fluorescence images were compared with standard color images, as well as references values obtained by conventional colorimetry. Tomatoes were stored at $25^{\circ} \mathrm{C}$ for $9 \mathrm{~d}$ after harvest. The effectiveness of color and fluorescence images were compared in terms of the timing and sensitivity of RGB ratios in these images. The compounds responsible for color and fluorescence images were also discussed based on lycopene content and absorption band position observed in the excitation-emission matrix (EEM).

\section{Materials and methods}

\subsection{Tomato samples}

Tomato plants (cultivar Momotaro, currently the most popular in Japan) grown hydroponically in a greenhouse at Ehime University, Matsuyama, Ehime, Japan were used. Details of cultivation are described in a previous study (Takahashi et al., 2018). Tomato seeds were sown on July 21 , 
102

Netherlands) on September 12, 2017. The plants were irrigated with a nutrient solution containing the following fertilizers; $\mathrm{KNO}_{3}, \mathrm{Ca}\left(\mathrm{NO}_{3}\right)_{2}, \mathrm{Ca}\left(\mathrm{NO}_{3}\right)_{2} \cdot 4 \mathrm{H}_{2} \mathrm{O}, \mathrm{NH}_{4} \mathrm{NO}_{3}, \mathrm{H}_{3} \mathrm{PO}_{4}, \mathrm{KH}_{2} \mathrm{PO}_{4}, \mathrm{KCl}$, $\mathrm{K}_{2} \mathrm{SO}_{4}, \quad \mathrm{MgSO}_{4} \cdot 7 \mathrm{H}_{2} \mathrm{O}, \quad \mathrm{Fe}-\mathrm{EDTA}, \quad \mathrm{H}_{3} \mathrm{BO}_{3}, \quad \mathrm{MnSO}_{4} \cdot 4 \mathrm{H}_{2} \mathrm{O}, \quad \mathrm{ZnSO}_{4} \cdot 7 \mathrm{H}_{2} \mathrm{O}, \quad \mathrm{CuSO}_{4} \cdot 5 \mathrm{H}_{2} \mathrm{O}$, $\mathrm{NaMoO}_{4} \cdot 2 \mathrm{H}_{2} \mathrm{O}$, at an electrical conductivity of $0.2 \mathrm{~S} \mathrm{~m}^{-1}$ and a $\mathrm{pH}$ of 5.5-6.5.

Tomatoes (31 fruit in total) were harvested at the onset of the red color stage on June 19, 2018 (hue angle $<53.0$ and lightness of color $\left(\mathrm{L}^{*}\right)<53.0$ measured by a colorimeter as described below). Upon harvesting, the fruit were sent to Kyoto University using a commercial delivery service that maintained the tomatoes at $0-10{ }^{\circ} \mathrm{C}$ during transportation $(24 \mathrm{~h}$ period $)$. After arrival, the tomatoes were stored in the dark at $25 \pm 1{ }^{\circ} \mathrm{C}$ ) in an incubator (AS ONE Corp., Japan). The relative humidity was maintained at $85 \pm 5 \%$. At each sampling during storage, three or four fruit were used from each day measurement. Sampling occurred at one- or two-day intervals from when the tomatoes were put in storage up to $9 \mathrm{~d}$.

\subsection{Colorimeter}

For the measurement of L*, a*, b* values a colorimeter CR-200 (Konica Minolta, Inc., Japan) was used under a $\mathrm{C}$ illuminant condition. A circle area $(8 \mathrm{~mm}$ diameter) was measured. The results presented here at each sampling represents the average of four fruit, where each fruit is measured at three locations (once at blossom end and twice at the equator: $180^{\circ}$ between positions) were used to obtain an average value for each sample. The error bar represents the standard error (S.E.) of four fruit.

\subsection{Color and fluorescence image}


For the capture of color and fluorescence images, two light sources and a CMOS camera were used. A schematic diagram of the setup is shown in Fig. 1. The black filled boxes represent the two light sources. The open box represents the camera. For the color images, four halogen lamps (4700 K) were used with a $45^{\circ}$ incidence angle to the sample; arranged orthogonal to each other. The average irradiance at $50-\mathrm{mm}$-height above the sample plane was $2.5 \mathrm{~W} \mathrm{~m}^{-2}$. Five C-PL filters (Kenko Tokina Corp., Japan) were also placed in front of the four halogen lamps and the camera to reduce halation with a crossed geometry.

For fluorescence image capture, a ring-type 365-nm LEDs (CCS Inc., Japan) were used at a normal incidence. The full width at half maximum (FWHM) for these LEDs was around $10 \mathrm{~nm}$. The average irradiance at the sample plane was $6.9 \mathrm{~W} \mathrm{~m}^{-2}$, when placed $190 \mathrm{~mm}$ below the light source. To filter out reflected UV light reaching the camera, a long-pass glass filter was placed between the camera and the UV light source (50\% cut at $430 \mathrm{~nm})$. This filter operated as a UVcut-like filter, but permitted a transmission of 365 -nm-light at $0.3 \%$. This ensured two main phenomena (reflection and fluorescence) were observed in the fluorescence image; hereafter referred to as the "fluorescence image".

For both image types, we used a high-resolution CMOS camera EOS Kiss x7 (Canon Inc., Japan) with parameters set as ISO 100, F-6.3 and shutter exposure $1 / 25 \mathrm{~s}$ and $4 \mathrm{~s}$ for both the color and fluorescence images. The camera was calibrated with the same white balance card (Xrite Corp., US).

\subsection{Analysis of color and fluorescence color}

For the analysis of three measurements (a colorimeter, color images and fluorescence images), 
the $R G B$ values were converted to a ratio (for example $R /(R+G+B)$ ) by dividing the total intensity of $\mathrm{R}, \mathrm{G}, \mathrm{B}$ channel. This procedure compensates for variations in lightness of color ( $\left.\mathrm{L}^{*}\right)$ and enhances the chromaticity in an arbitrary lightness plane on each day of measurement. The RGB values were further normalized by the mean value at day 1 to compare the performance between the color and the fluorescence images. The RGB ratio was expressed as the mean value with a S.E.

For the extraction of RGB values from the two images, a region of interest (ROI) was set. As shown in Fig. 4, there were apparently three different regions at the blossom end: The distal area (d in Fig. 4), vascular bundles (v in Fig. 4) and the other remaining zone. For all analyses, the whole blossom end area except for the distal area was set as the ROI. analysis was conducted using Image J software (NIH).

\subsection{Lycopene content}


This extraction procedure was repeated with $15 \mathrm{~mL}$ of acetone. After the extraction, the solution was adjusted to $50 \mathrm{~mL}$ by adding further acetone to the flask. The solution was filtered using a $0.45 \mu \mathrm{m}$ disposal filter (AS ONE Corp., Japan). The absorbance of the supernatant was measured using a spectrophotometer V-670 (JASCO Corp., Japan). The lycopene concentration was calculated using a molar absorption coefficient of $3150 \%{ }^{-1} \mathrm{~cm}^{-1}$ at $505 \mathrm{~nm}$ in acetone (Nagata et al., 2007), which is the peak wavelength of lycopene. The lycopene content was calculated by dividing the content in the solution by the tomato aliquot mass. The results were expressed in $\mathrm{mg}$ $\mathrm{kg}^{-1}$ lycopene on a fresh weight basis.

\subsection{Excitation-emission matrix}

To identify potential components associated with changes in the fluorescence images, an excitation-emission matrix (EEM) was measured using a spectrofluorometer FP-8300 (JASCO Corp., Japan). The spectral range of excitation and emission were $250-660 \mathrm{~nm}$ and $280-700 \mathrm{~nm}$, respectively. The band width was set to be $5 \mathrm{~nm}$ for both slits. The photomultiplier tube (PMT) sensitivity was set to prevent saturation with a response time and scan speed of $50 \mathrm{~ms}$ and 5000 $\mathrm{nm} \min ^{-1}$, respectively. Different tomatoes were selected for EEM measurement and image capture. A pericarp slice (20 $\mathrm{mm}$ diameter with 3-mm-thick) from the equatorial zone was attached to the sample holder (20-mm diameter quartz window). The incident and detection angles were $30^{\circ}$ and $60^{\circ}$, respectively.

\section{Results}


To investigate the color changes of tomato from the red stage, $L^{*}, a^{*}, b^{*}$ values were measured

by a colorimeter. Previously, the color of tomatoes has been evaluated based mainly on a* or a*/b* (López Camelo and Gómez, 2004; Bui et al., 2010), but more recent studies have also used other color values in the $\mathrm{L}^{*} \mathrm{a} \mathrm{b}^{*}$ - or $\mathrm{L} * \mathrm{C} * \mathrm{~h}$-color spaces. (Dhakal and Baek, 2014; Torres et al., 2015; van Roy et al., 2017). From a human perception perspective, the color expressed in the $\mathrm{L} * \mathrm{C} * \mathrm{~h}$-color space is more easily understandable.

Fig. 2 shows the hue angle and lightness of tomatoes during the storage at $25^{\circ} \mathrm{C}$. The hue angle and the lightness initially decreased until day 3. The chroma (i.e. saturation in HSI-color space) fluctuated $(27.8 \pm 1.0,29.1 \pm 1.4$ to $30.2 \pm 0.9$ for 1,5 to $9 \mathrm{~d})$. This decreasing trend of hue angle during storage of our red tomatoes was consistent with previous reports for yellow (Pek et al., 2010; Thai et al., 1990) and green (Dhakal and Baek, 2014) tomatoes at harvest. This indicates the decreasing trend of hue angle was consistent regardless of maturity stage at harvest. In $\mathrm{L} * \mathrm{a} * \mathrm{~b} *$-color space, $\mathrm{a} *$ increased until day 5 , while $\mathrm{b} *$ decreased rapidly at day 3 . The $\mathrm{a} / \mathrm{b} *$ parameter increased until day 3 , being inversely correlated with the hue angle changes, as

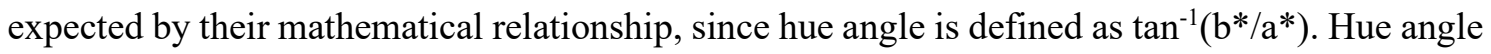
and lightness, obtained by the colorimeter, were useful to monitor the quality degradation of tomatoes that were harvested at the red stage and stored at $25^{\circ} \mathrm{C}$ until at least day 3 .

To compare with fluorescence, an optimum wavelength region, in other words, a color channel ( $R, G, B)$ is important. To reduce the undesirable effect of lightness and enhance chromaticity (the best estimate of color without intensity), the RGB values were divided by $\mathrm{R}+\mathrm{G}+\mathrm{B}$ and normalized by their initial values for each ratio to compare the performance between the color and fluorescence images. 
Fig. 3 shows the relative RGB ratios of tomato during storage. The R ratio increased while the

213 G ratio decreased. The B ratio rapidly increased at day 3, decreasing slightly there afterwards.

214 The decrease of hue angle in Fig. 2 is associated with an increase in the R ratio and decrease in the $\mathrm{G}$ ratio. This could be due to accumulation of lycopene, which absorbs green light and reflects red light (Choudhary et al., 2009; Zhu et al., 2015). Even though the tomato appears reddish, in color, not only the $\mathrm{R}$ ratio, but the $\mathrm{G}$ ratio also has the potential to monitor tomato quality degradation when harvested at the red stage and stored at $25^{\circ} \mathrm{C}$ until day 5 .

\subsection{Changes in $R G B$ ratio from the color and fluorescence images}

The color and fluorescence images of the tomatoes were evaluated using a non-contact image capture system. Fig. 4 shows typical color and fluorescence images of the same tomato. In the color images, the fruit appear to be reddish in color, but the distal area and vascular bundles exhibited a brownish and yellowish color, respectively. Meanwhile, the fluorescence images appear to be bluish overall, but the distal area appears to be whitish, while the vascular bundles a relatively dark blue, suggesting the presence of visible and invisible pigments were unevenly distributed at the blossom end of tomatoes. of images were examined for the ROI (the blossom end without the distal area). Fig. 5 shows the relative $\mathrm{RGB}$ ratios of tomato during the storage obtained by the color images. In the color image, the $\mathrm{R}$ ratio increased, while the $\mathrm{G}$ ratio decreased until day 3 . These trends are the same as those observed in the colorimeter measurements. The distal area exhibited a relatively unchanging profile except for the $\mathrm{G}$ ratio over the entire period $(1.00 \pm 0.02$ to $1.08 \pm 0.03$ for $\mathrm{R}$ ratio, $1.00 \pm$ 
234

0.05 to $0.79 \pm 0.07$ for $\mathrm{G}$ ratio and $1.00 \pm 0.04$ to $0.90 \pm 0.09$ for $\mathrm{B}$ ratio). This is associated with the existence of several brownish pigments, suggesting low amounts of lycopene in this area. The color images could effectively monitor tomato quality degradation after being harvested at the red stage and stored at $25^{\circ} \mathrm{C}$ up until day 3.

As a supplementary or alternative way to monitor tomato quality degradation, fluorescence images were examined. Fig. 6 shows the relative RGB ratios obtained from the fluorescence images. The trend for chromaticity was totally different from the colorimeter and color images, as shown in Figs. 3 and 5. Overall, the R ratio remained relatively unchanged (distal area excluded), while the $\mathrm{G}$ ratio increased and the $\mathrm{B}$ ratio decreased. Especially, the $\mathrm{G}$ ratio of the blossom end (distal area excluded) became higher at day 9. From this, it can be seen that the fluorescence image was sensitive to changes in tomato quality degradation over the entire storage period; much longer time provided by colorimeter and color images. Further details are explored in the discussion section.

The distal area was totally different from that of other areas. The most apparent difference was the significantly brighter spot in the distal area, as shown in Fig. 4. Although we hypothesized that this might have been caused by scattering or reflection of the excitation-light, further investigation showed the bright phenomenon occurred irrespective of lighting angle, thus we confirmed that this was caused by fluorescence.

\section{Discussion}

\subsection{Compounds affecting color images}

A knowledge of the chemical compounds associated with changes in the color image is 
important for future applications. The most dominant pigment in tomatoes is lycopene (up to 181

mg kg-1), which has a red color (Chaudhary et al., 2018; Martí et al., 2016). Absorption of

lycopene in tomatoes is known to peak around 500-550 $\mathrm{nm}$ (Zhu et al., 2015); absorbing green

blue light, but reflecting red light. This is reflected in the $\mathrm{G}, \mathrm{B}$ ratios, and the $\mathrm{R}$ ratio of the color images. In the current research, lycopene content was moderately correlated with the $\mathrm{R}$ ratio of the color images $(r=0.81)$, as shown in Fig. S1. The correlations with G and B ratio were negative; $r=-0.80$ and $r=-0.67$, respectively. This suggests that while lycopene content of lycopene is a major contributor, it does not explain all the variation.

Another group of pigments, carotenoids, are also known to contribute to color image differences in tomato, with up to $12 \mathrm{mg} \mathrm{kg}^{-1}$ of $\beta$-carotene (Chaudhary et al., 2018; Martí et al., 2016); orange in color. The absorption characteristics of $\beta$-carotene are almost the same as those of lycopene with the same basic 11-isoprenes structure; the main difference being a slight blueshift (Meléndez-Martínez et al., 2019). However, the content of $\beta$-carotene is only a small percentage of total carotenoid content (Martí et al., 2016). Thus, the contribution is relatively low. and carotenes (Meléndez-Martínez et al., 2015), but their absorption maxima are around 280 and $350 \mathrm{~nm}$ in petroleum ether, respectively (Meléndez-Martínez et al., 2019), thus they are colorless and not visually apparent in the color images. Another possible pigment affecting the color images is naringenin chalcone (up to $182 \mathrm{mg} \mathrm{kg}^{-1}$ ) (Martí et al., 2016), which is yellow. Naringenin chalcone absorbs purple light, thus it also might affect the B ratio of the color image. 
As indicated in the discussion above, lycopene is considered to be the component most closely associated with changes in the postharvest color images. Fig. 7 documents the measured changes in lycopene content during storage. Lycopene content increased from the start of storage from $37.3 \pm 2.8$ to $99.7 \pm 3.7 \mathrm{mg} \mathrm{kg}^{-1}$ at day 5 , stabilizing until day 7 , and then slightly increasing again up to $115.8 \pm 9.9 \mathrm{mg} \mathrm{kg}^{-1}$ at day 9. The overall trend was consistent with the observed changes in the RGB ratios of the color images, suggesting that lycopene is one of the most predominant pigment contributing to changes in the color images of the tomatoes in our storage condition.

\subsection{Compounds affecting fluorescence images}

The compounds associated with changes in the fluorescence images were inferred from the

EEM. Fig. 8 shows a typical EEM of a 3-mm-thick slice of tomato before and after storage. No

fluorescent peaks were observed in the visible region with excitation wavelengths used. This means that any fluorescent compounds present are colorless to the naked eye. around $420 \mathrm{~nm}$, for both excitations. These two peaks were highly correlated ( $r=0.91)$, as shown in Fig. S2. This indicates the two peaks are derived from the same compounds, although there might be another minor contribution from a different compound with an excitation at $250 \mathrm{~nm}$, as suggested by the negative intercept of 25 counts out of a total count of $50-120$ (i.e. $20-50 \%$ of total intensity comes from other minor compounds). Fig. S3 shows the excitation and emission spectra of all tomatoes measured (28 fruit). The excitation spectra had two peaks, indicating the compounds have two vibration structures. The most likely compounds that meet this criteria are phenolics (including flavonoid and some longer phenolic acid) or some vitamins, which exist in 
300

301

tomato (Chaudhary et al., 2018). We tentatively assigned the excitation peak at $350 \mathrm{~nm}$ to a flavonoid, consistent with that assigned by Lai et al. (2007).

There are also potential fluorescent compounds contributing to the observed excitation peaks. Carotenoids (i.e. phytoene and phytofluene) and simple phenolics with one aromatic ring (i.e. some amino acid and shorter phenolic acid) are other major groups known to have an absorption in the observed excitation range. But in the case of such compounds, only one absorption band would be expected between 250 and $600 \mathrm{~nm}$ of excitation, which contradicts the measured excitation spectra (Fig. S3).

Furthermore, carotenoids including lycopene (Song and Moore, 1974) and $\beta$-carotene (Gillbro and Cogdell, 1989; Song and Moore, 1974) are known to have extremely low quantum yields of less than $1 \times 10^{-4}$, compared to flavonoids $0.2-23 \times 10^{-3}$ (Park et al., 2013) and other simple phenolics $0.01-0.1$ (Wünsch et al., 2015). In addition, we could not find any fluorescence peak of lycopene in the measured EEM (Fig. 8). Lemos et al. (2015), who compared a lycopene standard with tomato extract, also could not find any lycopene fluorescence peak. This strongly suggests the fluorescent compounds observed in the fluorescence images are colorless pigments, except for carotenoids.

\subsection{Changes in fluorescence images}

In the EEM, excitation at 250 and $360 \mathrm{~nm}$ resulted in similar fluorescence emission spectra from tomatoes during storage (Fig. 9). In the spectra, there was a transition point at around 430 $\mathrm{nm}$, with relative intensity decreasing below $430 \mathrm{~nm}$ and increasing above $430 \mathrm{~nm}$ during storage. This was consistent with observed decreases in the $\mathrm{B}$ ratio and increases in the $\mathrm{R}$ and $\mathrm{G}$ ratios of 
322

323

326

the fluorescence image (Fig. 6).

Furthermore, several phase changes occurred in the observed fluorescence over time. From days 1 to 3 , the change was small, which corresponded with slight changes in the $G$ ratio over the same period (Fig. 6). Then, from days 3 to 5 , there was a jump in emissions above $430 \mathrm{~nm}$, with a corresponding slight increase in the G ratio (Fig. 6), followed by a stable period between days 5 to 7 , and then another period of increase from days 7 to 9 . In the later period, there was not only a broadening, but also a peak shift around $470 \mathrm{~nm}$. The second increase in the $\mathrm{G}$ ratio from days 7 to 9 might be affected by the two phenomena: broadening and shift of the emission spectra. This suggests at least two separate phenomena occurred with the fluorescent compounds, such as changes in the surrounding environment and the relative concentrations of these compounds, resulting in the broadening and the peak shift, respectively.

The RGB ratios of fluorescence images changed (Fig. 6) after the saturation of the RGB ratios in the color images (Fig. 5). This suggests that the changes in the fluorescent compounds were initiated after saturated accumulation of lycopene occurred. Since the ripening is the well programmed phenomenon controlled by the numerous genes, one hypothesis is the fluorescent compounds are regulated by the carotenoid-related genes such as PSY1, PDS and ZDS (Osorio et al., 2012). However, there was low correlation between the peak maxima at 250 and 360 of excitation with the lycopene content with correlation coefficient of -0.21 and -0.17 nor with the fluorescence emission ratio $(460 \mathrm{~nm} / 420 \mathrm{~nm}$ at the excitation of $360 \mathrm{~nm})$ with correlation coefficient of 0.54 . The changes in the fluorescent compound responsible for the fluorescence image was unrelated with the lycopene accumulation.

We acknowledge there are several limitations in this work. First, we could not investigate the 
344 optimum color spaces, white balance setting or correction of RGB sensitivity in the camera

345 capturing the fluorescence images. However, since the absolute value of fluorescence emissions

346 was difficult to standardize, the relative values were effective for our monitoring purposes.

347 Second, we have not directly identified the compounds associated with the quality changes

348 observed in the fluorescence images. In future work, we need to elucidate the mechanisms behind

349 the fluorescent phenomena. This mechanism would answer what metabolic pathways were

350 visualized in relation to the synthesis and degradation of the fluorescent compounds near the 351 surface.

\section{Conclusions}

In this study, we investigated the potential of UV-induced fluorescence images to nondestructively monitor quality degradation of tomato after being harvested at a red stage and stored at $25^{\circ} \mathrm{C}$. Fluorescence imaging (using excitation at $365 \mathrm{~nm}$ ) was found to be sensitive to tomato quality degradation for a longer period during storage than color imaging. In color and fluorescence images, the observed trends were opposite. In color images, the G ratio rapidly decreased for the first 3 to $5 \mathrm{~d}$, but after this, values became saturated. On the other hand, in fluorescence images, the G ratio increased continuously up to $9 \mathrm{~d}$ for tomatoes stored at $25^{\circ} \mathrm{C}$. harvested at different maturity stages, under different storage temperatures, harvesting seasons, cultivars and growth treatments. The identification of fluorescence compounds will also need to be included in future research work. Since in the postharvest period tomatoes are often transported and stored at least than ideal temperatures, this study demonstrates that fluorescence imaging can 
366

367

368

369

370

371

372 be used as a monitoring system of mature tomato quality degradation following harvesting right through to consumption.

Declaration of interest: none.

\section{Acknowledgements}

We thank Ms. Annisa Nurulhuda for the important preliminary study. We are also grateful to Mr. Miah Sumon, Dr. Muharfiza (Ministry of Agriculture, Indonesisa), Ms. Mayumi Kanayama, Ms. Hikari Nishio for technical supports. We also acknowledge Dr. Garry John Piller (Kyoto University) for his help and useful discussions. Financial support was provided by Matsushima Horticultural Development Foundation, Japan.

\section{References}

Ajlouni, S., Kremer, S., Masih, L., 2001. Lycopene content in hydroponic and non-hydroponic tomatoes during postharvest storage. Food Aust. 53, 195-196.

Arah, I.K., Kumah, E.K., Anku, E.K., Amaglo, H., 2015. An overview of post-harvest losses in tomato production in Africa: Causes and possible prevention strategies. J. Biol. 5, 78-88.

Baek, I.-S., Kim, M., Lee, H., Lee, W.-H., Cho, B.-K., 2014. Optimal fluorescence waveband determination for detecting defective cherry tomatoes using a fluorescence excitationemission matrix. Sensors 14, 21483-21496. https://doi.org/10.3390/s141121483

Barba, A.I.O., Hurtado, M.C., Mata, M.C.S., Ruiz, V.F., Tejada, M.L.S. de, 2006. Application of a UV-vis detection-HPLC method for a rapid determination of lycopene and $\beta$-carotene in 
vegetables. Food Chem. 95, 328-336. https://doi.org/10.1016/j.foodchem.2005.02.028

389

390

391

392

393

394

395

396

397

398

399

400

401

402

403

404

405

406

407

408

409

Bui, H.-T., Makhlouf, J., Ratti, C., 2010. Postharvest ripening characterization of greenhouse tomatoes. Int. J. Food Prop. 13, 830-846. https://doi.org/10.1080/10942910902895234

Chaudhary, P., Sharma, A., Singh, B., Nagpal, A.K., 2018. Bioactivities of phytochemicals present in tomato. J. Food Sci. Technol. 55, 2833-2849. https://doi.org/10.1007/s13197-018$3221-\mathrm{Z}$

Chilson, D., Delgado, A., Cecilia, M., Nunes, N., 2011. Shelf life of cluster tomatoes (Lycopersicum esculentum) stored at a non-chilling temperature and different relative humidity levels, in: Proc. Fla. State Hort. Soc. pp. 246-255.

Choudhary, R., Bowser, T.J., Weckler, P., Maness, N.O., McGlynn, W., 2009. Rapid estimation of lycopene concentration in watermelon and tomato puree by fiber optic visible reflectance spectroscopy. Postharvest Biol. Technol. 52, 103-109. https://doi.org/10.1016/j.postharvbio.2008.10.002

Clément, A., Bacon, R., Sirois, S., Dorais, M., 2015. Mature-ripe tomato spectral classification according to lycopene content and fruit type by visible, NIR reflectance and intrinsic fluorescence. Qual. Assur. Saf. Crops Foods 7, 747-756. https://doi.org/10.3920/QAS2014.0521

Dhakal, R., Baek, K.-H., 2014. Short period irradiation of single blue wavelength light extends the storage period of mature green tomatoes. Postharvest Biol. Technol. 90, 73-77. https://doi.org/10.1016/j.postharvbio.2013.12.007

Fagundes, C., Moraes, K., Pérez-Gago, M.B., Palou, L., Maraschin, M., Monteiro, A.R., 2015. Effect of active modified atmosphere and cold storage on the postharvest quality of cherry 
tomatoes. Postharvest Biol. Technol. 109, 73-81.

FAO, 2011. Global food losses and food waste - Extent, causes and prevention. Food and Agriculture Organization of the United Nations, Rome.

Gillbro, T., Cogdell, R.J., 1989. Carotenoid fluorescence. Chem. Phys. Lett. 158, 312-316. https://doi.org/10.1016/0009-2614(89)87342-7

Hoffmann, A.M., Noga, G., Hunsche, M., 2015. Fluorescence indices for monitoring the ripening of tomatoes in pre- and postharvest phases. Sci. Hortic. 191, 74-81. https://doi.org/10.1016/j.scienta.2015.05.001

Ito, H., Horie, H., 2009. Proper solvent selection for lycopene extraction in tomatoes and application to a rapid determination. Bull. Natl. Inst. Veg. Tea Sci. Jpn. 8, 165-173. 397. https://doi.org/10.3390/bios5030367 
Martí, R., Roselló, S., Cebolla-Cornejo, J., 2016. Tomato as a source of carotenoids and polyphenols targeted to cancer prevention. Cancers 8, 58 . https://doi.org/10.3390/cancers8060058

Meléndez-Martínez, A.J., Mapelli-Brahm, P., Benítez-González, A., Stinco, C.M., 2015. A comprehensive review on the colorless carotenoids phytoene and phytofluene. Arch. Biochem. Biophys. 572, 188-200. https://doi.org/10.1016/j.abb.2015.01.003

Meléndez-Martínez, A.J., Stinco, C.M., Mapelli-Brahm, P., 2019. Skin carotenoids in public health and nutricosmetics: The emerging roles and applications of the UV radiationabsorbing colourless carotenoids phytoene and phytofluene. Nutrients 11, 1093. https://doi.org/10.3390/nu11051093

Nagata, M., Noguchi, Y., Ito, H., Imanishi, S., Sugiyama, K., 2007. A simple spectrophotometric method for the estimation of $\alpha$-carotene, $\beta$-carotene and lycopene concentrations in carrot acetone extracts. Nippon Shokuhin Kagaku Kogaku Kaishi 54, 351355. https://doi.org/10.3136/nskkk.54.351

Osorio, S., Alba, R., Nikoloski, Z., Kochevenko, A., Fernie, A.R., Giovannoni, J.J., 2012. Integrative comparative analyses of transcript and metabolite profiles from pepper and tomato ripening and development stages uncovers species-specific patterns of network regulatory behavior. Plant Physiol. 159, 1713-1729. https://doi.org/10.1104/pp.112.199711

Park, H.-R., Daun, Y., Park, J.K., Bark, K.-M., 2013. Spectroscopic properties of flavonoids in various aqueous-organic solvent mixtures. Bull. Korean Chem. Soc. 34, 211-220. https://doi.org/10.5012/bkcs.2013.34.1.211 
454

455

456

457

458

459

460

461

462

463

464

465

466

467

468

469

470

Pek, Z., Helyes, L., Lugasi, A., 2010. Color changes and antioxidant content of vine and postharvest- ripened tomato fruits 45,3 .

Slimestad, R., Verheul, M., 2009. Review of flavonoids and other phenolics from fruits of different tomato (Lycopersicon esculentum Mill.) cultivars. J. Sci. Food Agric. 89, 12551270. https://doi.org/10.1002/jsfa.3605

Song, P.-S., Moore, T.A., 1974. On the photoreceptor pigment for phototropism and phototaxis: Is a carotenoid the most likely candidate? Photochem. Photobiol. 19, 435-441. https://doi.org/10.1111/j.1751-1097.1974.tb06535.x

Takahashi, N., Yokoyama, N., Takayama, K., Nishina, H., 2018. Estimation of tomato fruit lycopene content after storage at different storage temperatures and durations. Environ. Control Biol. 56, 157-160. https://doi.org/10.2525/ecb.56.157

Thai, C.N., Shewfelt, R.L., Gamer, J.C., 1990. Tomato color changes under constant and variable storage temperatures: Empirical models. Trans. ASAE 33, 0607-0614. https://doi.org/10.13031/2013.31374

Toor, R.K., Savage, G.P., 2006. Changes in major antioxidant components of tomatoes during post-harvest storage. Food Chem. 99, 724-727. https://doi.org/10.1016/j.foodchem.2005.08.049

Torres, I., Pérez-Marín, D., Haba, M.-J.D. la, Sánchez, M.-T., 2015. Fast and accurate quality assessment of Raf tomatoes using NIRS technology. Postharvest Biol. Technol. 107, 9-15. https://doi.org/10.1016/j.postharvbio.2015.04.004

van Roy, J., Keresztes, J.C., Wouters, N., De Ketelaere, B., Saeys, W., 2017. Measuring colour of vine tomatoes using hyperspectral imaging. Postharvest Biol. Technol. 129, 79-89. 
476 https://doi.org/10.1016/j.postharvbio.2017.03.006

477 Wünsch, U.J., Murphy, K.R., Stedmon, C.A., 2015. Fluorescence quantum yields of natural 478 organic matter and organic compounds: Implications for the fluorescence-based 479 interpretation of organic matter composition. Front. Mar. Sci. 2.

$480 \quad$ https://doi.org/10.3389/fmars.2015.00098

481 Zhu, Q., He, C., Lu, R., Mendoza, F., Cen, H., 2015. Ripeness evaluation of 'Sun Bright' 482 tomato using optical absorption and scattering properties. Postharvest Biol. Technol. 103, 483 27-34. https://doi.org/10.1016/j.postharvbio.2015.02.007 


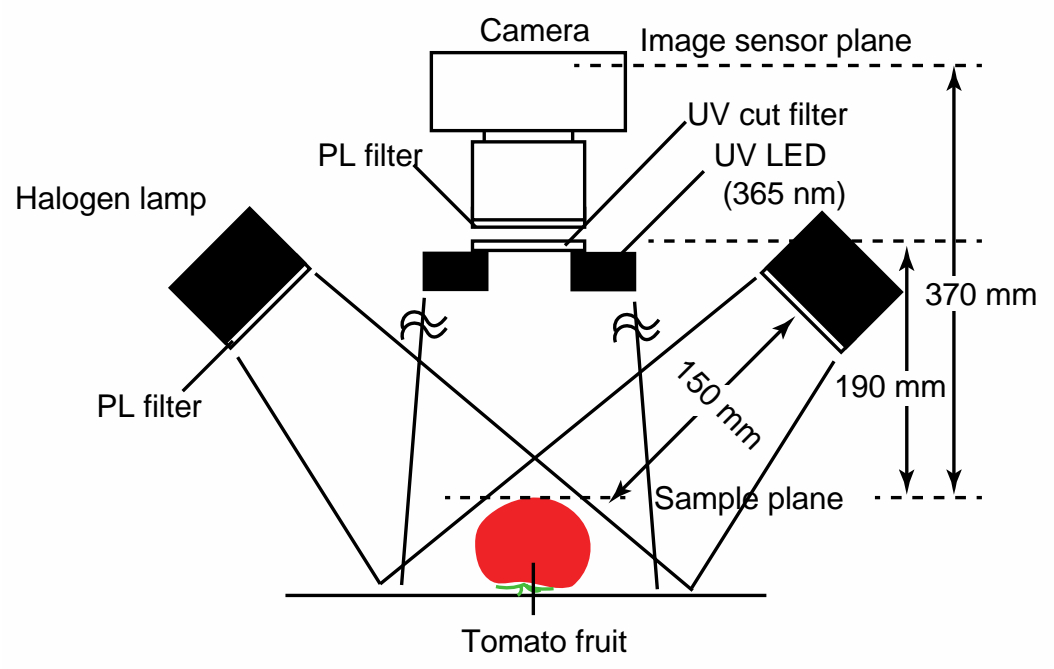

Fig. 1. Schematic diagram of the image capture setup in side view 

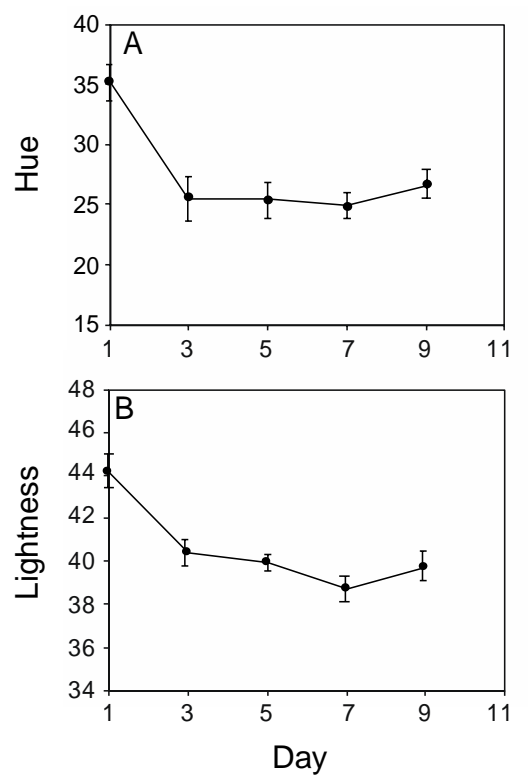

Fig. 2. Changes in hue angle (A) and lightness (B) of color of tomato measured by the colorimeter: tomatoes were harvested at the red stage and stored at $25^{\circ} \mathrm{C}$ until day $9-$ the error bar represents the S.E. of four different fruits 

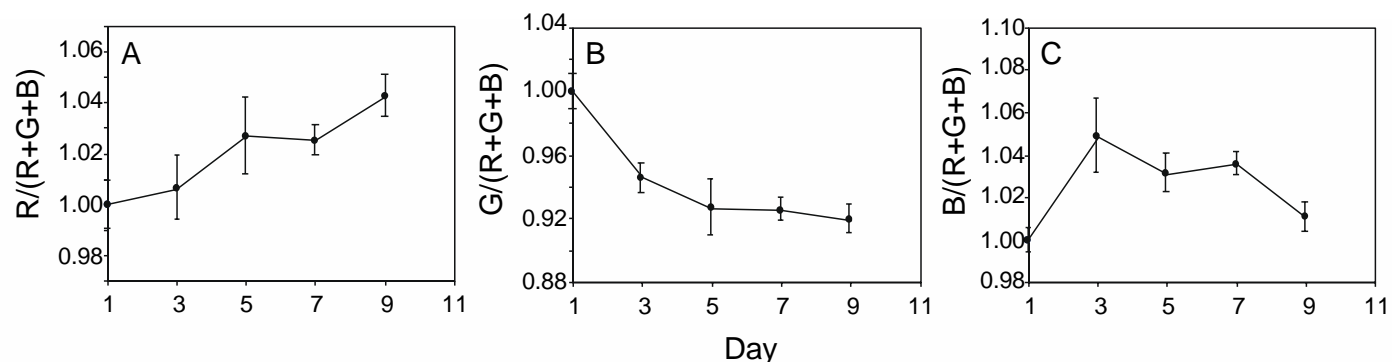

Fig. 3. Changes in relative $\mathrm{R}(\mathrm{A}), \mathrm{G}(\mathrm{B})$, and $\mathrm{B}(\mathrm{C})$ ratios of color of tomatoes measured by the colorimeter: tomatoes were harvested at the red stage and stored at $25^{\circ} \mathrm{C}$ until day 9 - the error bar represents the S.E. of four different fruits 


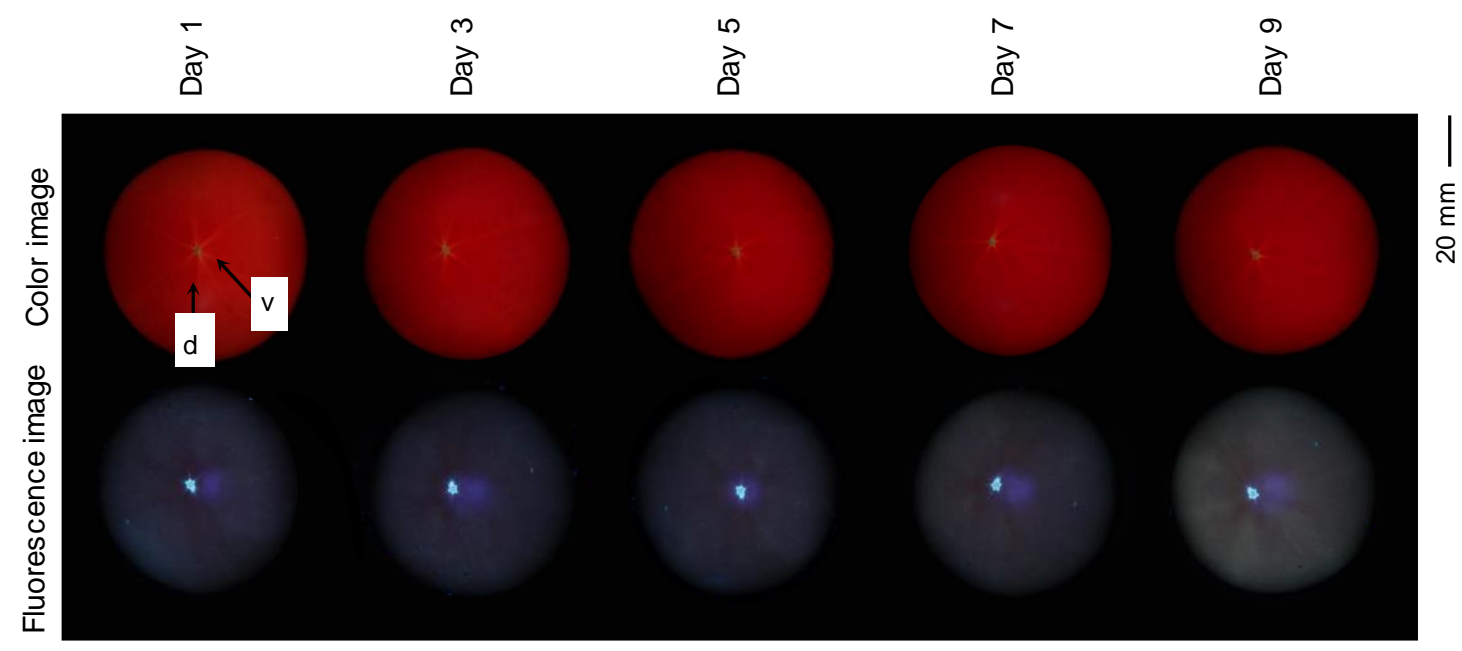

Fig. 4. Color and fluorescence images of tomatoes at the blossom end: tomatoes were harvested at the red stage and stored at $25^{\circ} \mathrm{C}$ until day 9 - the arrows indicate the vascular bundles (v) and the distal area (d) 

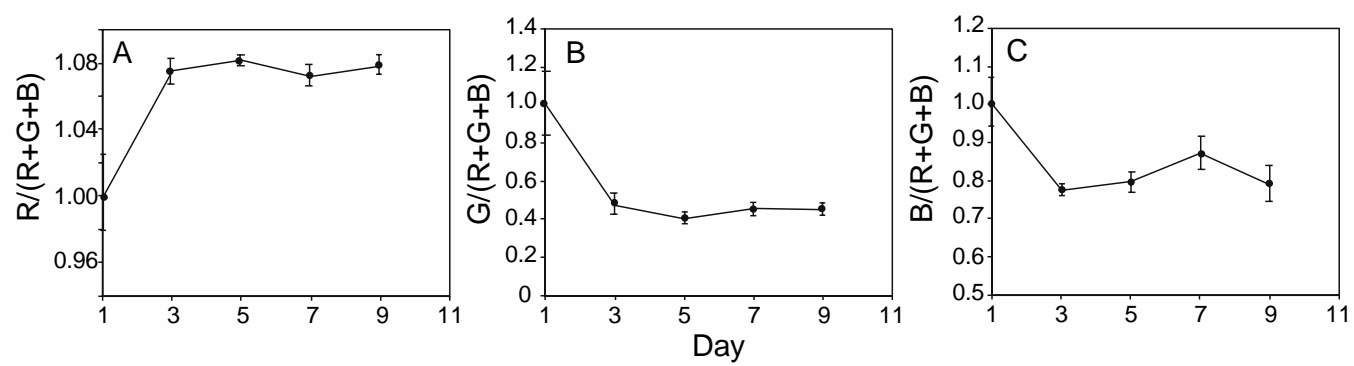

Fig. 5. Relative R (A), G (B), and B (C) ratios of color of tomatoes calculated from the color images: tomatoes were harvested at the red stage and stored at $25^{\circ} \mathrm{C}$ until day 9 , and the colors were averaged for the blossom end without distal area - the error bar represents the S.E. of the same three fruits 

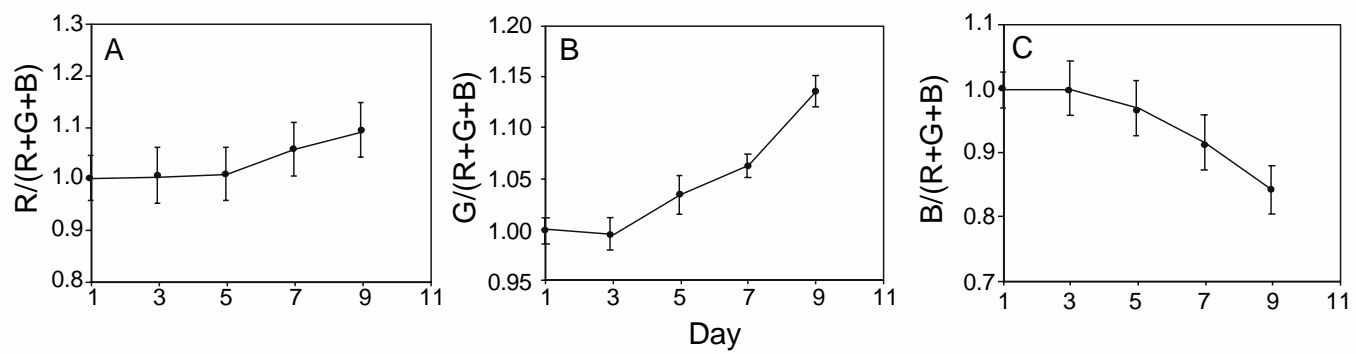

Fig. 6. Relative R (A), G (B), and B (C) ratios of fluorescence color of tomatoes calculated from the fluorescence images: tomatoes were harvested at the red stage and stored at $25^{\circ} \mathrm{C}$ until day 9, and the colors were averaged for the blossom end without distal area - the error bar represents the S.E. of the same three fruits 


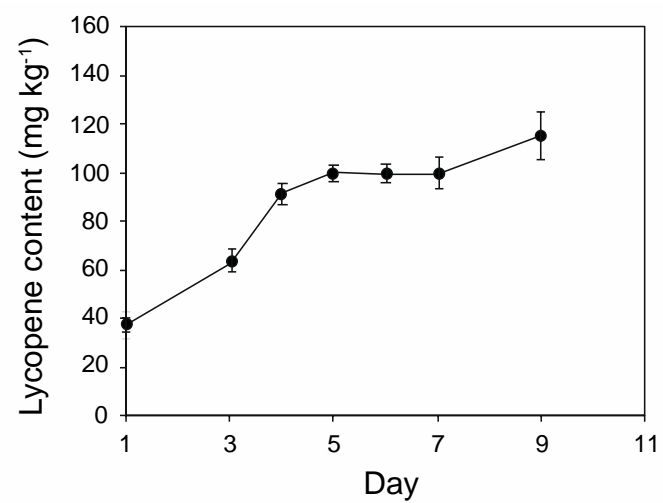

Fig. 7. Lycopene content of tomatoes harvested at the red stage and stored at $25^{\circ} \mathrm{C}$ until day 9 (fresh weight basis) — the error bar represents the S.E. of four different fruits 

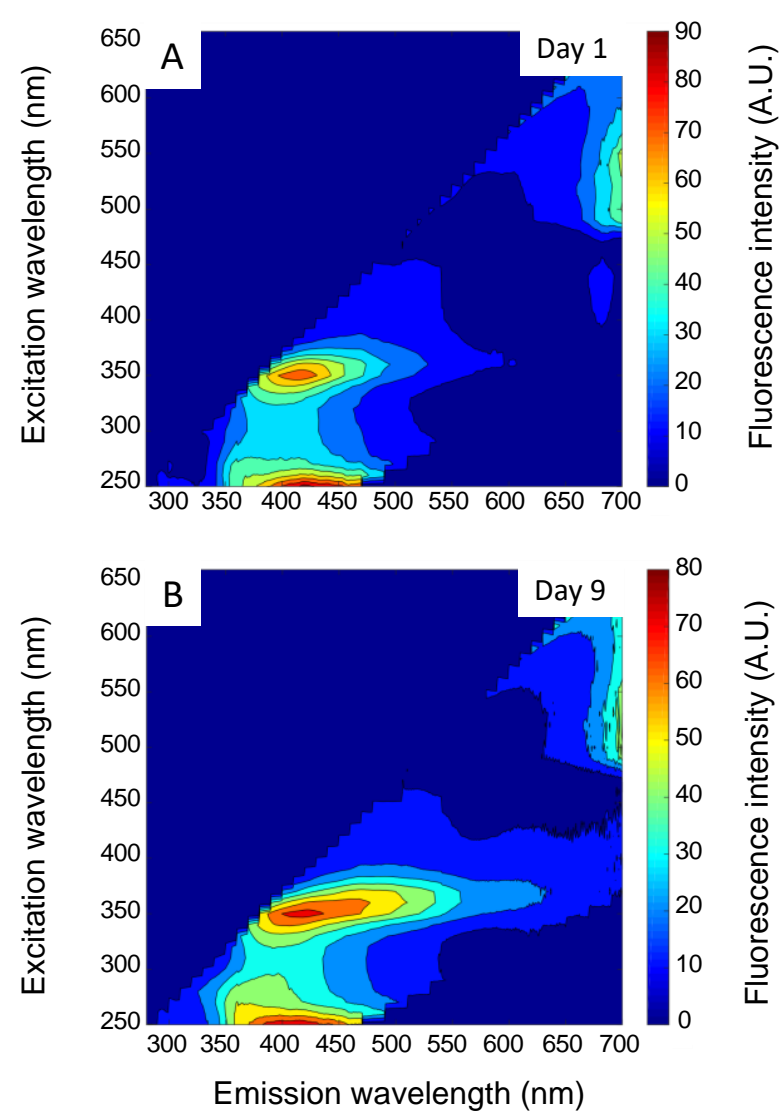

Fig. 8. Typical excitation-emission matrix (EEM) of the tomato pericarp: the tomatoes were harvested at the red stage (A) and stored at $25^{\circ} \mathrm{C}$ until day $9(\mathrm{~B})$, and the tomato pericarp was molded using a razor $20 \mathrm{~mm}$ in diameter and $3 \mathrm{~mm}$ in thickness - the fluorescence emission spectra at approximately 370, 470, and $540 \mathrm{~nm}$ were slightly distorted because of the filter in the device 


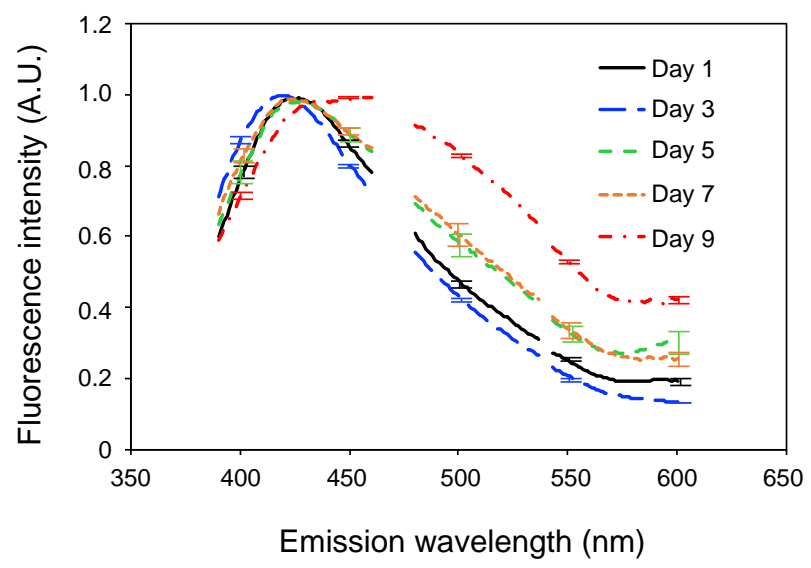

Fig. 9. Relative fluorescence emission spectra of tomato harvested at the red stage and stored at $25^{\circ} \mathrm{C}$ until day 9: the excitation wavelength was $360 \mathrm{~nm}$, the spectra were normalized at the peak maxima, and the spectra at approximately 470 and $540 \mathrm{~nm}$ were cut to remove the spectral distortion caused by the filter in the device - the spectra are the mean with S.E. of four different fruits 


\section{Supplemental materials}

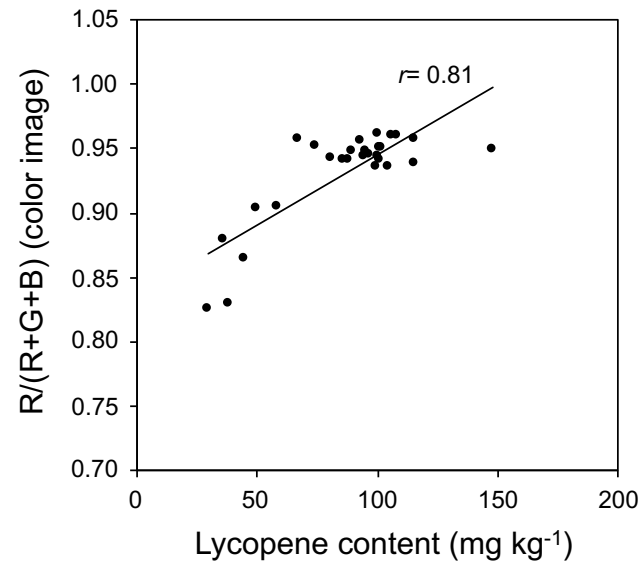

Fig. S1. Relationship between the R ratio of color image and the lycopene content during storage at $25^{\circ} \mathrm{C}$ (28 fruit) 


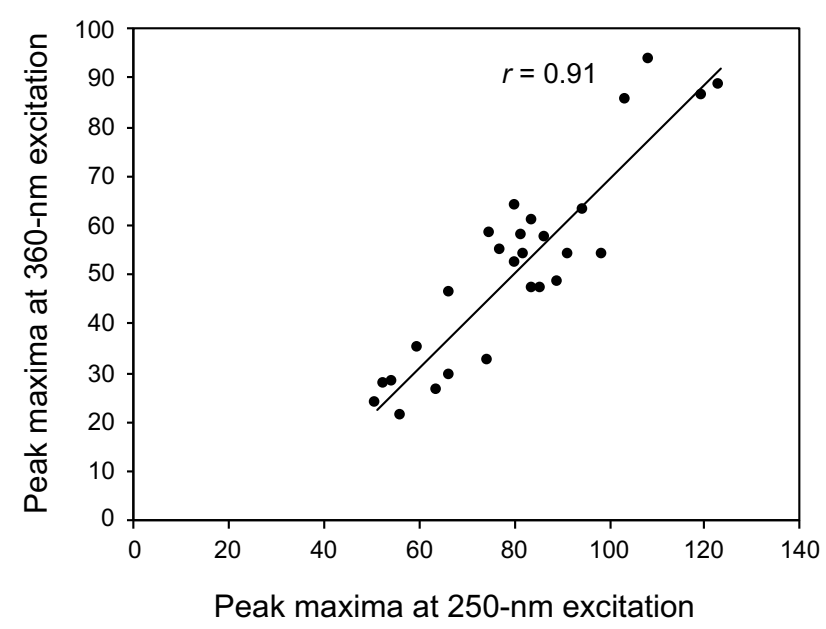

Fig. S2. Relationship between the fluorescence peak maxima at 360 and $250 \mathrm{~nm}$ of excitation (28 fruit) 


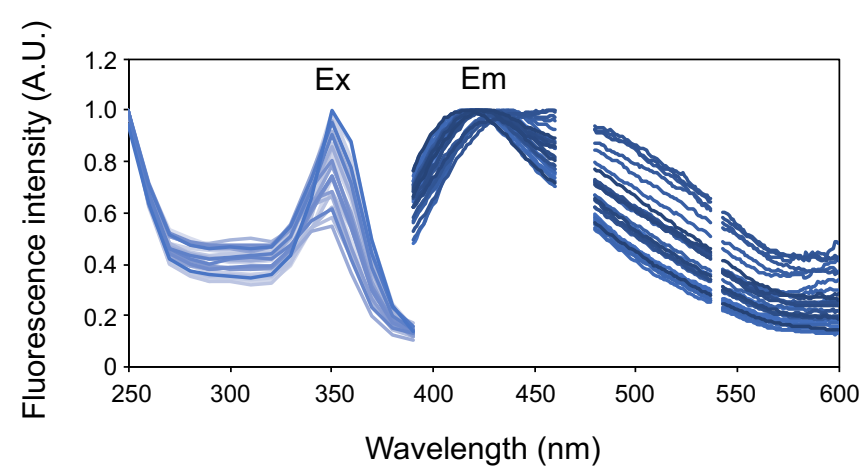

Fig. S3. Relative fluorescence excitation and emission spectra of all tomatoes measured (28 fruit): the excitation spectra were measured at $420 \mathrm{~nm}$ of emission, the emission spectra were measured at $360 \mathrm{~nm}$ of excitation, the excitation and emission spectra were normalized at the peak maxima, and the spectra at approximately 470 and $540 \mathrm{~nm}$ were cut to remove the spectral distortion resulting from the filter in the device 